\title{
Simulation and modeling of two-level DC/DC boost converter using ARX, ARMAX, and OE model structures
}

\author{
M.A.N. Amran, A.A. Bakar, M.H.A. Jalil, M.U. Wahyu, A.F.H.A. Gani \\ Faculty of Electrical and Electronic Engineering, Universiti Tun Hussein Onn Malaysia, Malaysia
}

\begin{tabular}{l} 
Article Info \\
\hline Article history: \\
Received Oct 11, 2019 \\
Revised Dec 12, 2019 \\
Accepted Dec 26, 2019 \\
\hline
\end{tabular}

\section{Keywords:}

DC/DC converter

System identification

Two-level boost converter

\begin{abstract}
This paper presents simulation and modeling of two-level DC/DC boost converter using system identification technique. The main objective is to identify the unknown mathematical model from designated converter that has 2 modes of operation. Signals from the converter were processed based on the impulse response from input and output voltages, which were in time domain data. Auto Regressive with eXogenous (ARX), Auto Regressive Moving Average with eXogenous (ARMAX), and Output-Error (OE) model structure techniques had been employed to generate a model from the converter, whose validation was based on coefficient of determination (R2) or best fits criterion. The result shows that the ARX model structure produced the best model with $94.03 \%$, compared to ARMAX and OE with $93.70 \%$ and $92.25 \%$ respectively. In terms of stability for open-loop analysis, the ARX model structure gave the most stable system.
\end{abstract}

Copyright $(2020$ Institute of Advanced Engineering and Science. All rights reserved.

\section{Corresponding Author:}

Afarulrazi Abu Bakar,

Faculty of Electrical and Electronic Engineering,

Universiti Tun Hussein Onn Malaysia,

86400 Parit Raja Batu Pahat, Johor, Malaysia.

Email: afarul@uthm.edu.my

\section{INTRODUCTION}

DC/DC converters are known as means for reducing or increasing input voltage [1]. There are various types of DC/DC converters, such as boost, buck-boost and buck converter. Boost converter is one of the most popular converters to step up the output voltage. Boost converters are widely used in various applications such as in renewable energy system, electrical and electronic devices, as well as electrical vehicles [2-5]. Lately, researchers particularly studying control system have gained more interests in voltage regulation issues related to DC/DC boost converter [4].

Two-level DC/DC boost converter is a multiple conventional boost converter that is arranged in parallel manners. The advantages of a $\mathrm{N}$-level boost converter, compared to conventional boost converter topologys, are ability to reduce the input and output current ripple [6,7], reduce switches stress and increase the load transient [8-13]. Pulse-width modulation (PWM) signals of two-level boost converter are appointed by 180 degree phase-shifted at each level to turn-on and turn-off the MOSFETs [14]. Recently, researches have primarily focused on design architecture and structure, such as less weight, reduction in size, component count and cost. However, the concern on statistical methods to build mathematical models measured data for further determination of dynamic system behavior, which can provide further information and robustness of the system, are less deliberated.

System identification is common method of creating a dynamic mathematical system model using the system input and output signal measurement [15]. Modeling a two-level boost converter using system identification offers more detailed characteristic on the dynamic behavior and the transient response of the converter [16-19]. Furthermore, the system behavior can be further investigated from the model, such as the overshoot, undershoot and steady-state operation. System identification techniques with parametric and non- 
parametric method have been applied in digital and analog controlled DC/DC converters [20, 21]. Three models have been considered in this study via simulation, which are Auto Regressive with eXogenous (ARX), Auto Regressive Moving Average with eXogenous (ARMAX), and Output-error (OE) model structure. Auto Regressive with eXogenous model (ARX) is the most common linear model used in system identification, as it provides the simplest model structure, along with excellent performance [22-25].

The remaining of this paper is organized as follows: Section 2 explains the principle operation of two-level boost converter, Section 3 describes the procedure to perform the system identification process, and Section 4 gives an overview about the results and discussion. Lastly, Section 5 gives a conclusion about overall simulation results.

\section{PRINCIPLE OPERATION OF TWO-LEVEL BOOST CONVERTER}

The proposed circuit configuration of two-level boost converter is as shown in Figure 1. The circuit consists of two diodes, two switches, two inductors, a capacitor and an inductor. The diodes, switches, and inductors are connected in parallel.

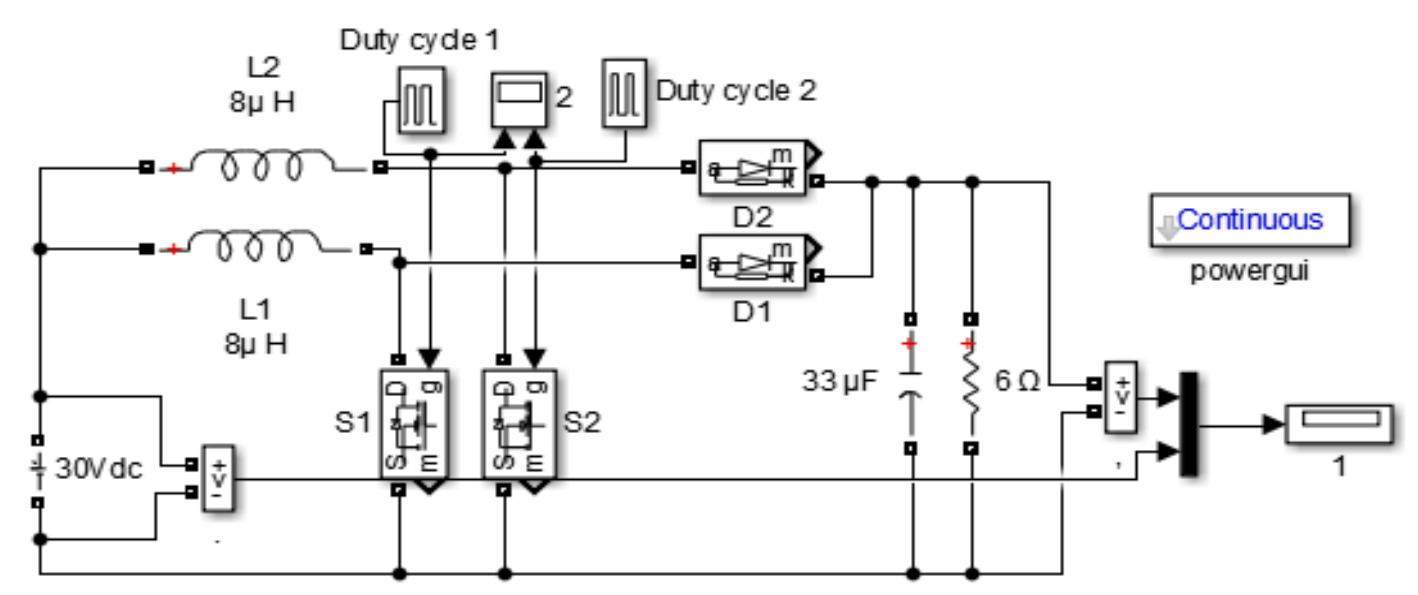

Figure 1. Two-level boost converter

Table 1 shows the mode of operation of the two-level boost converter. In mode 1 , switch $\mathrm{S}_{1}$ is closed while switch $S_{2}$ is opened. Meanwhile, inductor for $L_{1}$ will be recharged, and inductor $\mathrm{L}_{2}$ will be discharged, thus the current in inductor $\mathrm{L}_{2}$ decreases. In this case, diode $\mathrm{D}_{1}$ acts as a forward bias, therefore current will flow through it; while diode $\mathrm{D}_{2}$ acts as reversed bias. Switch $\mathrm{S}_{2}$ will be closed while switch $\mathrm{S}_{1}$ will be opened. Conversely, inductor $\mathrm{L}_{2}$ is recharged while inductor $\mathrm{L}_{1}$ is discharged; thus current through inductor $\mathrm{L}_{1}$ decreases. In this case, diode $\mathrm{D}_{2}$ acts as forward bias, therefore current will flow through it, while diode $\mathrm{D}_{1}$ acts as reversed bias.

Table1. Mode Operation of Two-Level Boost Converter

\begin{tabular}{ccc}
\hline Time & Switches, $S_{n}$ & Diode, $D_{n}$ \\
\hline$t_{0}-t_{1}$ (Mode 1) & S1 closed S2 opened & Diode D1 reversed bias while D2 forward bias \\
$t_{1}-t_{2}$ (Mode2) & S2 closed S1 opened & Diode D2 reversed bias while D1 forward bias \\
\hline
\end{tabular}

\section{IDENTIFICATION PROCEDURE}

System identification is a sub discipline of control engineering which can be used to determine the mathematical model of the measured system. Figure 2 shows the contrivance to perform the system identification for the two-level boost converter. The procedure includes simulation, data collection, model order determination, model estimation, and model validation. If the outcome is unacceptable, repeated process loop as cycle 1 , cycle 2 , cycle 3 , or cycle 4 . 


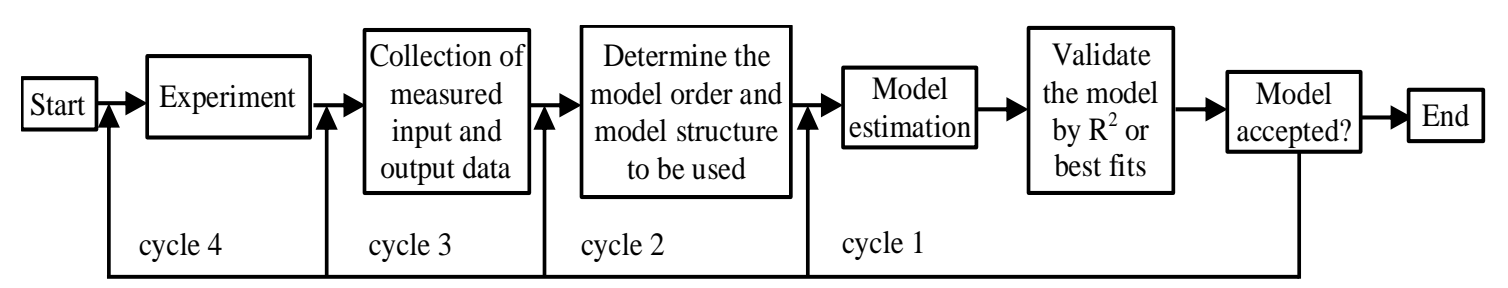

Figure 2. System identification procedure

\subsection{Model Structure}

Figure 3 shows three model structures for system identification. Based on the block in Figure 3(a), it shows the structure of the ARX model, where e $(t)$ represents the disturbance, $y(t)$ is the output of the system, and $u(t)$ is the input system. In this study, ARX was considered as the main model as it is the simplest model compared to other models. ARX model is the best and most efficient polynomial estimation whose solution gives a minimal global loss function. This solution is important especially for higher orders. The structural equation of the ARX model is given by (1).

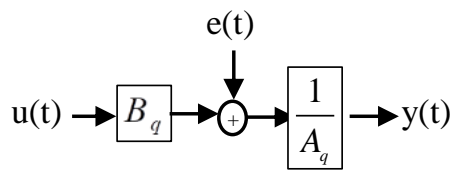

(a)

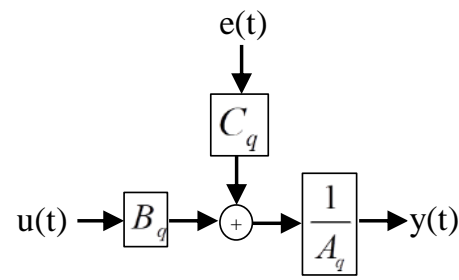

(b)

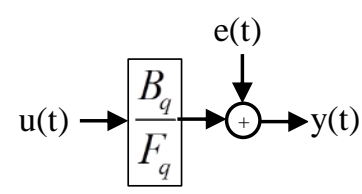

(c)

Figure 3. Model structures of (a) ARX, (b) ARMAX and (c) OE

$$
A_{q} y(t)=B_{q} u(t)+e(t)
$$

Figure 3 (b) shows the structure for ARMAX model. The structure of the ARMAX model differs from the ARX model, including the perturbations that occur at the beginning of the process. The ARMAX model is capable of handling of disturbance modeling better than the ARX model. The structural equation of the ARMAX model is given by (2).

$$
A_{q} y(t)=B_{q} u(t)+C_{q} e(t)
$$

Figure 3 (c) shows the OE model structure, in which no parameter is used to describe the disturbance. As shown in (3) shows the structural equation for OE model structure.

$$
y(t)=\frac{B_{q}}{F q} u(t)+e(t)
$$

\subsection{Model Development}

For the model order of ARX, ARMAX, and OE model, five number of orders had been picked randomly. The selection of model order was by increasing the order until obtaining the maximum value of $\mathrm{R}^{2}$, where ' 1 ' denotes having the best model. The order was selected as stated in Table 2.

Table 2. Five random orders for ARX, ARMAX, and OE

\begin{tabular}{ccc}
\hline ARX & ARMAX & OE \\
\hline$(1,1,1)$ & $(1,1,1,1)$ & $(2,1,1)$ \\
$(2,1,1)$ & $(2,2,2,1)$ & $(2,2,1)$ \\
$(3,2,1)$ & $(3,2,2,1)$ & $(3,1,1)$ \\
$(4,2,1)$ & $(4,2,2,1)$ & $(4,1,1)$ \\
$(5,4,1)$ & $(4,1,1,1)$ & $(4,2,1)$ \\
\hline
\end{tabular}




\section{RESULTS AND DISCUSSION}

Figure 4 and Table 3 show five random structures of the ARX model and the best fits for the random orders, respectively. Figure 4 shows the graph output voltage versus sample time. The graph was plotted based on $(1,1,1),(2,1,1),,(3,2,1),(4,2,1)$ and $(5,4,1)$ orders to distinguish the difference of each order. Based on Table 3 , the lowest best fits gives value of $1.36 \%$ with $(1,1,1)$ order, while the highest is $(5,4,1)$ with $96.81 \%$ best fits. The input and output data from the two-level boost converter had been compared, and the best result from the ARX model structure yielded $96.81 \%$ best fits. The discrete time polynomial for ARX model structure for system identification in MATLAB/Simulink software can be expressed as (4). The best mathematical models for ARX model structure $(5,4,1)$ are expressed as (5) and (6).

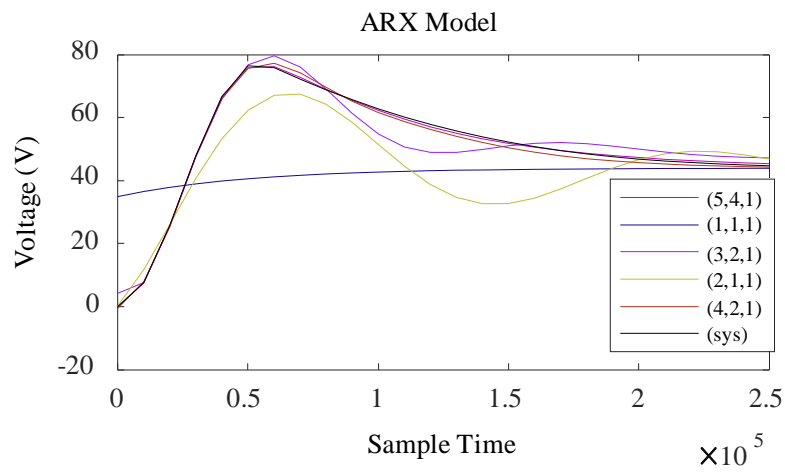

Table 3. ARX Model based Order

\begin{tabular}{cc}
\hline Model order & Best fits \\
\hline$(1,1,1)$ & $1.36 \%$ \\
$(2,1,1)$ & $41.78 \%$ \\
$(3,2,1)$ & $76.70 \%$ \\
$(4,2,1)$ & $94.03 \%$ \\
$(5,4,1)$ & $96.81 \%$
\end{tabular}

Figure 4. Measured and simulated ARX model structure

$$
A\left(Z^{-1}\right) y(t)=B\left(Z^{-1}\right) u(t)+e(t)
$$

The mathematical model for output is expressed as

$\therefore A\left(Z^{-1}\right)=1-2.043 Z^{-1}+1.762 Z^{-2}-0.9202 Z^{-3}+0.2919 Z^{-4}-0.04167 Z^{-5}$

The mathematical model for input is expressed as

$\therefore B\left(Z^{-1}\right)=0.07159 Z^{-1}$

Figure 5 shows the voltage versus sample time graph for ARMAX model structure. The graph consists of $(1,1,1,1),(4,1,1,1),(3,2,2,1),(4,2,2,1)$, and $(2,2,2,1)$ ARMAX model orders. Table 4 shows the comparison for best fits for five random model orders. Table 4 shows that the lowest best fits is from $(1,1,1,1)$ with $2.60 \%$, while the highest is from $(4,1,1,1)$ with $93.7 \%$ best fits.

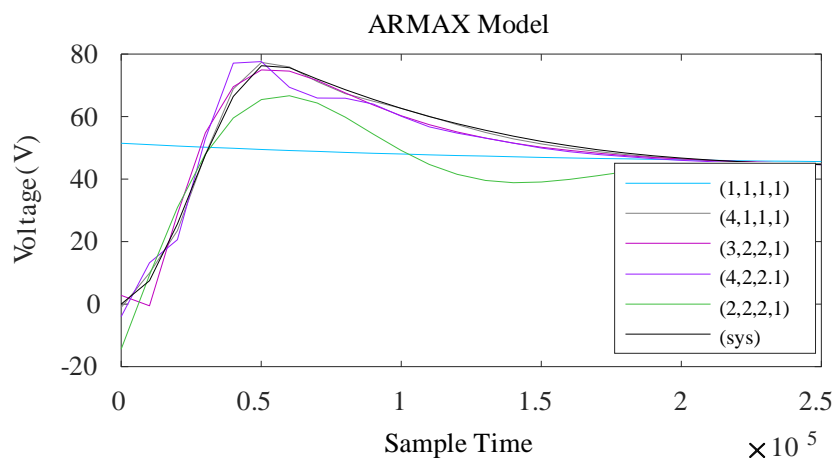

Table 4. ARMAX Model based Order

\begin{tabular}{cc}
\hline Model order & Best fits \\
\hline$(1,1,1,1)$ & $2.60 \%$ \\
$(2,2,2,1)$ & $49.46 \%$ \\
$(4,2,2,1)$ & $80.47 \%$ \\
$(3,2,2,1)$ & $85.53 \%$ \\
$(4,1,1,1)$ & $93.70 \%$ \\
\hline
\end{tabular}

Figure 5. Measured and simulated ARMAX model structure 
The discrete time polynomial equation for ARMAX model structure is expressed as (7). The mathematical models for $(4,1,1,1)$ are expressed as (8), (9) and (10). For discrete time polynomial of ARMAX model structure,

$$
A\left(Z^{-1}\right) y(t)=B\left(Z^{-1}\right) u(t)+C\left(Z^{-1}\right) e(t)
$$

The mathematical model for output is expressed as:

$\therefore A\left(Z^{-1}\right)=1-1.691 Z^{-1}+1.305 Z^{-2}-0.7489 Z^{-3}+0.2193 Z^{-4}$

While the mathematical model for input is expressed as:

$\therefore B\left(Z^{-1}\right)=0.07162 Z^{-1}$

And the mathematical model for disturbance is expressed as:

$\therefore C\left(Z^{-1}\right)=1-Z^{-1}$

Figure 6 shows the graph voltage versus sample time for five random orders for OE model. The graph consists of orders of $(2,2,1),(2,1,1),(3,1,1),(4,2,1)$ and $(4,1,1)$. The comparison for bests fits for five random orders is shown in Table 5. According to Table 5, the lowest best fits is from $(2,1,1)$ with $19.96 \%$, while the highest best fits is $(4,1,1)$ with $92.25 \%$ in value.

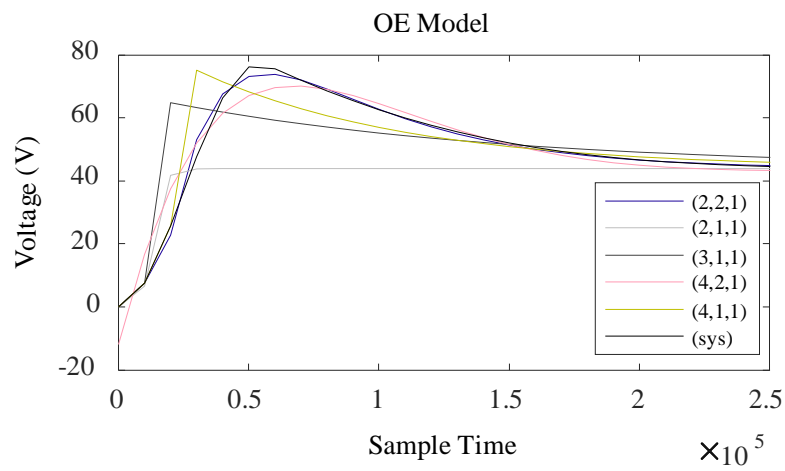

Table 5. OE model based order

\begin{tabular}{cc}
\hline Model order & Best fits \\
\hline$(2,1,1)$ & $19.96 \%$ \\
$(3,1,1)$ & $43.41 \%$ \\
$(4,1,1)$ & $63.43 \%$ \\
$(2,2,1)$ & $75.22 \%$ \\
$(4,2,1)$ & $92.25 \%$ \\
\hline
\end{tabular}

Figure 6. Measured and simulated OE model structure

The discrete time polynomial equation for OE model structure is shown in (11). As shown in (12) and (13) show the mathematical models for $(4,2,1)$. Discrete time polynomial for OE model structure is expressed as

$$
y(t)=\frac{B\left(Z^{-1}\right)}{F\left(Z^{-1}\right)} u(t)+e(t)
$$

The mathematical model for input side is expressed as

$$
\therefore B\left(Z^{-1}\right)=0.0261 Z^{-1}+0.0261 Z^{-2}-0.0261 Z^{-3}+0.0261 Z^{-4}
$$

and,

$\therefore F\left(Z^{-1}\right)=1-1.429 Z^{-1}+0.5003 Z^{-2}$

Among the models generated by ARX, ARMAX, and OE, the ARX model structure gave the best best fits of $96.81 \%$ compared to those of ARMAX and OE model structures, with $93.70 \%$ and OE 92.25\%, respectively. 


\subsection{Stability for Open-Loop $(5,4,1)$ ARX Model Structure}

Normally, frequency response can be obtained through the mathematical model of the system. System identification provides a frequency response generated from the mathematical model of the model. Frequency response can be used to predict the behavior of open-loop system in closed-loop system. In order to find the robustness of the system, gain margin and phase margin are taken into account to determine the stability of open-loop system. Figure 7 shows the frequency response for ARX for $(5,4,1)$ model order.
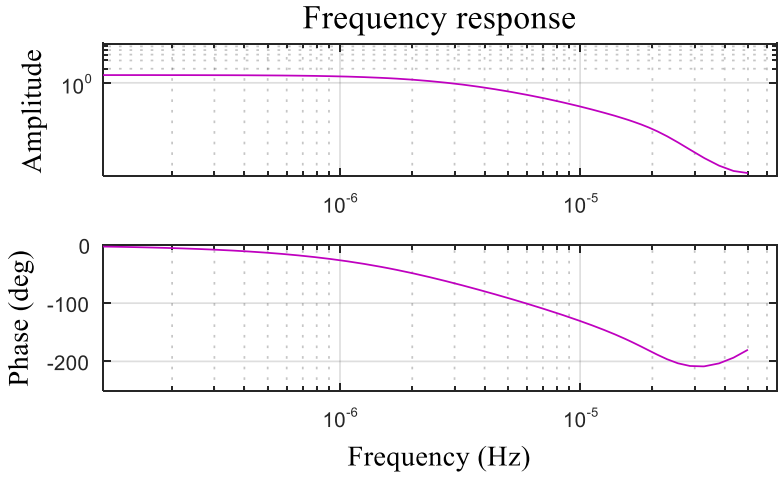

Figure 7. Frequency response for $(5,4,1)$ ARX model

The gain crossover frequency for ARX model structure shown in Figure 7 is about $3.4 \mathrm{e}^{-6} \mathrm{~Hz}$, whereby the phase margin is about 91 degrees. For the phase crossover frequency, the value is $9.4 \mathrm{e}^{-6} \mathrm{~Hz}$, whereby the gain margin is about 0.65 . The plot shows that the frequency response for $(5,4,1)$ gave a stable open-loop system. This is because the crossover frequency met the requirement of -180 degrees when the magnitude plot intersected $0 \mathrm{~dB}$ line

\section{CONCLUSION}

This paper has presented a study on two-level DC/DC boost converter with system identification approach using MATLAB/Simulink software. The two-level DC/DC boost converter, which operates in discontinuous conduction mode, can be implemented in system identification to generate mathematical model for control purpose. The generated ARX, ARMAX and OE model structures have more than 90 percent similarity with the actual model. Therefore, system identification offers a simple technique to generate system dynamic and mathematical model for the two-level boost converter.

\section{ACKNOWLEDGEMENTS}

The authors would like to express their deepest appreciation to Universiti Tun Hussein Onn Malaysia for supporting this research under TIER 1 Vot U195 research.

\section{REFERENCES}

[1] S. H. Liao, J. H. Teng, and S. W. Chen, "Bidirectional DC-DC converter with high step-down and step-up voltage conversion ratio," in 2016 IEEE 2nd Annual Southern Power Electronics Conference, SPEC 2016, 2016, pp. 1-6.

[2] F. S. Alargt, A. S. Ashur, M. A. Shrud, and A. H. Kharaz, "Interleaved Boost DC-DC Converter Using DeltaSigma Modulation Suitable for Renewable Energy Applications,” Int. J. Comput. Electr. Eng., vol. 6, no. 4, 2014.

[3] A. Farooq, Z. Malik, Z. Sun, and G. Chen, "A Review of Non-Isolated High Step-Down Dc-Dc Converters," Int. J. Smart Home, vol. 9, no. 8, pp. 133-150, 2015.

[4] W. Jiang, S. H. Chincholkar, and C. Y. Chan, "Investigation of a Voltage-Mode Controller for a dc-dc Multilevel Boost Converter," IEEE Trans. Circuits Syst. II Express Briefs, vol. 65, no. 7, pp. 908-912, 2018.

[5] A. N. De Paula, D. De Castro Pereira, W. J. De Paula, and F. L. Tofoli, "An extensive review of nonisolated DC-DC boost-based converters," 2014 11th IEEE/IAS Int. Conf. Ind. Appl. IEEE INDUSCON 2014 - Electron. Proc., 2014.

[6] A. A. Bakar, M. U. Wahyu, A. Ponniran, and T. Taufik, "Simulation and analysis of multiphase boost converter with soft-switching for renewable energy application," Int. J. Power Electron. Drive Syst., vol. 8, no. 4, pp. 1894-1902, 2017. 
[7] M. A. Devi, K. Valarmathi, and R. Mahendran, "Ripple current reduction in interleaved boost converter by using advanced PWM techniques," in Proceedings of 2014 IEEE International Conference on Advanced Communication, Control and Computing Technologies, ICACCCT 2014, 2015, no. 978, pp. 115-119.

[8] B. Axelrod, Y. Beck, and Y. Berkovich, "High step-up DC-DC converter based on the switched-coupled-inductor boost converter and diode-capacitor multiplier: steady state and dynamics," IET Power Electron., vol. 8, no. 8, pp. 1420-1428, 2015.

[9] K. H. Jasmine and C. R. Raj, "A high gain boost converter with input current ripple reduction," in 2014 International Conference on Circuits, Power and Computing Technologies, ICCPCT 2014, 2014, pp. 455-460.

[10] F. Zhang, F. Z. Peng, and Z. Qian, "Study of the multilevel converters in DC-DC applications," PESC Rec. - IEEE Annu. Power Electron. Spec. Conf., vol. 2, pp. 1702-1706, 2004.

[11] M. Rezvanyvardom, E. Adib, and H. Farzanehfard, "New interleaved zero-current switching pulse-width modulation boost converter with one auxiliary switch," IET Power Electron., vol. 4, no. 9, pp. 979-983, 2011.

[12] J. Wen, T. Jin, and K. Smedley, “A New Interleaved Isolated Boost Converter for High Power Applications," Twenty-First Annu. IEEE Appl. Power Electron. Conf. Expo. 2006. APEC ’06., pp. 79-84, 2006.

[13] A. F. H. A. Gani, A. A. Bakar, A. Ponniran, M. Hussainar, and M. A. N. Amran, "Design and development of PWM switching for 5-level multiphase interleaved DC / DC boost converter," Indones. J. Electr. Eng. Comput. Sci., vol. 17, no. 1, pp. 131-140, 2020.

[14] A. A. Bakar, W. M. Utomo, S. A. Zulkifli, E. Sulaiman, M. Z. Ahmad, and M. Jenal, "DC-DC Interleaved Boost Converter using FPGA," IEEE Conference on Clean Energy and Technology (CEAT) DC-DC, 2013, pp. 97-100.

[15] M. Al-Greer, M. Armstrong, M. Ahmeid, and D. Giaouris, "Advances on system identification techniques for DCDC switch mode power converter applications," IEEE Trans. Power Electron., vol. 34, no. 7, pp. 6973-6990, 2019.

[16] V. Valdivia, A. Barrado, A. Lázaro, P. Zumel, C. Raga, and C. Fernández, "Simple modeling and identification procedures for 'black-box' behavioral modeling of power converters based on transient response analysis," IEEE Trans. Power Electron., vol. 24, no. 12, pp. 2776-2790, 2009.

[17] M. M. Peretz and S. Ben-Yaakov, "Time-domain identification of pulse-width modulated converters," IET Power Electron., vol. 5, no. 2, pp. 166-172, 2012.

[18] M. Algreer, M. Armstrong, and D. Giaouris, "System identification of PWM dc-dc converters during abrupt load changes," in IECON Proceedings (Industrial Electronics Conference), 2009, pp. 1788-1793.

[19] L. Arnedo, R. Burgos, D. Boroyevich, and F. Wang, "System-Level Black-Box Dc-to-Dc Converter Models," 2009 Twenty-Fourth Annu. IEEE Appl. Power Electron. Conf. Expo., pp. 1476-1481, 2009.

[20] A. Davoudi, N. Kong, H. Behjati, M. Hagen, and E. Oettinger, "Automated system identification and controller tuning for digitally controlled dc-dc converters," IET Power Electron., vol. 5, no. 6, pp. 765-772, 2012.

[21] N. Beohar, V. N. K. Malladi, D. Mandal, S. Ozev, and B. Bakkaloglu, "Online Built-In Self-Test of High Switching Frequency DC - DC Converters Using Model Reference Based System Identification Techniques,” IEEE Trans. Circuits Syst. I Regul. Pap., vol. 65, no. 2, pp. 818-831, 2018.

[22] F. Alonge, R. Rabbeni, M. Pucci, and G. Vitale, "Identification and Robust Control of a Quadratic DC/DC Boost Converter by Hammerstein Model,” IEEE Trans. Ind. Appl., vol. 51, no. 5, pp. 3975-3985, Sep. 2015.

[23] M. Al-Greer, M. Armstrong, M. Ahmeid, and D. Giaouris, "Advances on System Identification Techniques for DCDC Switch Mode Power Converter Applications," IEEE Trans. Power Electron., vol. 8993, no. c, pp. 1-17, 2018.

[24] N. Ismail, M. H. F. Rahiman, and M. N. Taib, "Investigation of ARX model on partial input-output data in heating process,” Proc. - 2011 IEEE Control Syst. Grad. Res. Colloquium, ICSGRC 2011, pp. 7-11, 2011.

[25] M. H. Marzaki, M. Tajjudin, R. Adnan, M. H. F. Rahiman, and M. H. A. Jalil, "Comparison of different model structure selection using R2, MDL and AIC criterion," Proc. - 2013 IEEE 4th Control Syst. Grad. Res. Colloquium, ICSGRC 2013, pp. 80-85, 2013.

\section{BIOGRAPHIES OF AUTHORS}

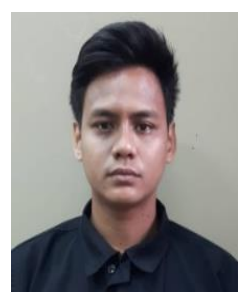

Mohd Azlee Noor Amran was born in Selangor, Malaysia on May 5, 1995. He received Bachelor's degree in Electrical Engineering from Universiti Tun Hussein Onn Malaysia (UTHM), Parit Raja, Batu Pahat, Johor, Malaysia in 2019. He is currently pursuing M.S. degree in Electrical Engineering at UTHM. His current research interests include the areas of DC/DC converter, system identification and controller design.

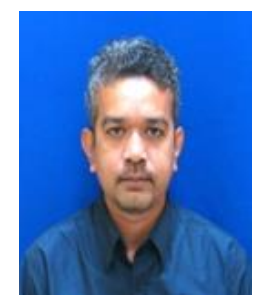

Afarulrazi Abu Bakar was born in Johor, Malaysia on May 18, 1980. He received B.Eng. degree in Electrical Engineering from Universiti Teknologi Mara (UiTM), Malaysia, in 2004 and M.Eng and Ph.D, degrees from Universiti Tun Hussein Onn Malaysia (UTHM), in 2019 and 2007, respectively. He has been working as a lecturer at the Department of Electrical Power Engineering, Faculty of Electrical and Electronic Engineering, UTHM, since 2007. His current research interests include renewable energy application, DC/DC converters, multiple-input converters, multiphase converters, resonant converters, and advanced controller design. 

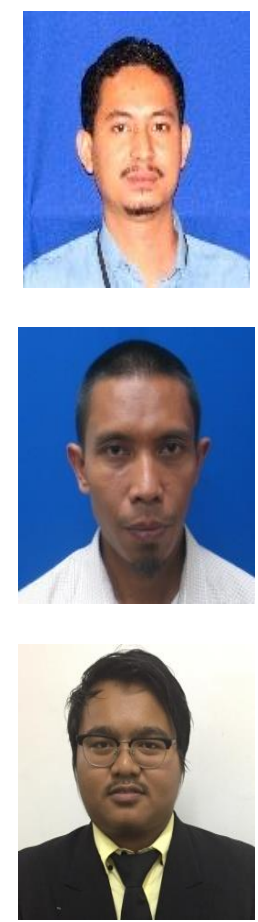

Mohd Hafiz A. Jalil @ Zainuddin was born in Kluang, Johor, Malaysia, in 1980. He received B.Eng degree in Electrical Engineering, Universiti Teknologi Mara (UiTM), Malaysia in 2004, Masters in Electrical Engineering (Mechatronics) in 2006 and Ph.D, degrees from Universiti Teknologi Mara (UiTM), Malaysia in 2019. He has been working as a lecturer at Faculty of Electrical and Electronic Engineering, Universiti Tun Hussein Onn Malaysia since 2006. His research interest is related to process control, application of advanced control, instrumentation and system identification.

Wahyu Mulyo Utomo was born in Pati, Indonesia, in 1969. He received B.S. degree in electrical engineering from Universitas Brawijaya Malang, in 1993, M.S. degree in electrical engineering from the Institute Sepuluh Nopember Surabaya, in 2000, and Dr. Eng Degree from Universiti Teknologi Malaysia in 2007. He is currently an associate professor at the Electrical Power Engineering Department, Faculty of Electrical and Electronic Engineering, Universiti Tun Hussein Onn Malaysia. His current research interests include the area ofpower electronics and motor drives control.

Ahmad Faiz Hilmi Abdul Gani was born in Kedah, Malaysia in 1995. He received B.Eng in Electrical Engineering from Universiti Tun Hussein Onn Malaysia (UTHM), Parit Raja, Batu Pahat, Johor, Malaysia in 2018. He is currently pursuing M.S. degree in Electrical Engineering at UTHM. His current research interests include the area of renewable energy application, multilevel DC/DC converter and soft-switching converter. 